\title{
THE ANALGESIC EFFICACY OF KINESIOLOGY TAPING IN DELAYED ONSET MUSCLE SORENESS (DOMS)
}

\author{
Julia Kruszyniewicz, A, B, D Karolina Skonieczna-Żydecka, ${ }^{1, A, ~ C, ~ D ~}$ \\ Radosław Sroka, ${ }^{2, A, D}$ Grażyna Adler, D, E \\ ${ }^{1}$ Department of Gerontobiology, Pomeranian Medical University, Szczecin, Poland \\ 2 Faculty of Physical Culture and Health Promotion, University of Szczecin, Poland

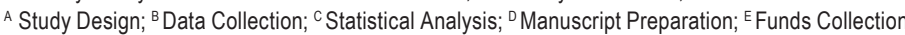 \\ Address for correspondence: \\ Karolina Skonieczna-Żydecka \\ Żołnierska 48, 71-210 Szczecin, Poland \\ Email: karzyd@pum.edu.pl
}

\begin{abstract}
Ahstract. Aims and scope: Delayed Onset Muscle Soreness (DOMS) develops after intense physical activity and its mechanisms are due to inflammation. Kinesiology Taping (KT) improves microcirculation, supports myofascial functions and relieves the tissue. The aim of this study was to verify whether KT has an analgesic action in the DOMS and whether somatotype is associated with this action. Materials and Methods: There were 20 healthy subjects aged $27.7 \pm 6.4$ years with moderate or high physical activity included into the study. The training with emphasis on eccentric muscle work was performed. Somatotype of respondents was assessed by Heath-Carter method. While DOMS occurred, KT muscle application on one of the limbs was done. For the next five days subjects filled out questionnaires in which they served intensity of pain on the basis of Visual Analogue Scale (VAS). Results and conclusions: In the limb where KT application was used a significant $(p<0.05)$ reduction in the intensity of DOMS compared to the limb without application was observed. It was found that the somatotype has no effect on the reduction of DOMS ( $>0.05)$. Conclusions: KT exhibits analgesic properties in DOMS. Somatotype has no relation to the effectiveness of KT analgesic efficacy in DOMS.
\end{abstract}

Key world: Delayed Onset Muscle Soreness, Kinesiology Taping, analgesic efficacy

\section{Introduction}

Delayed onset muscle soreness (DOMS) is an example of exercise-induced muscle damage (EIMD) first described in 1902 by Hough. DOMS arises in 6 to 12 hours after physical activity and lasts 5 to 7 days. The characteristic symptoms include pain, tenderness and stiffness of muscles. The strongest pain is felt 24 and up to 72 hours after exercise, which correlates with the highest levels of markers of muscle damage in serum (Gomes et al., 2014; Hough, 1902; Kanda et al., 2013). The symptoms are of diverse nature ranging from slight muscle stiffness to severe, debilitating pain, limiting the possibility of movement. Tenderness is usually observed in distal muscle, within 24 to 48 hours after exercise spreads to the proximal parts. It was suggested that this is due to the accumulation of a number of nociceptors at the point where the muscle passes into tendon. In addition, the 
cross-arrangement of the muscle fibers in this area reduces its resistance to high tensile strength, making it more susceptible to microinjuries in comparison to other muscle regions (Garrett, 1996; Gulick, Kimura, 1996).

Delayed onset muscle soreness occurs due to overloading the muscle, in particular a large amount of eccentric contractions. When the external load exceeds the capacity of the muscle, its stretches and active tension occurs thus increasing the risk of damaging the musculoskeletal connection (Armstrong, Warren, 1993; Stauber, 1989).

Although ultimately EIMD supports the regeneration process and increases the strength of tissue during the active phase of EIMD it increases the risk of injury associated with impaired proprioception, mobility of joints and muscle strength. In women increased muscle stiffness and further reduction in the flexibility of ligaments was observed. These disorders and especially pain develop to protect the tissue from additional damage (Cheung et al., 2003; Dutto, Braun, 2004; Hedayatpour, Falla, 2014; Lee et al., 2013; Serinken et al., 2013).

Kinesiology Taping (KT) is a method of physiotherapy, which aims to restore the body functions using sensory-motor system communication rules. Through the application of flexible Kinesio Tex patch (K-Active Tape), the therapy effects on the skin surface receptors and Ruffini corpuscles, responsible for the degree of tension and stretch of the skin. These receptors are related to A-a motor neurons and sarkomeres, which allows achieving the therapeutic effects (Kase, 2000; Mikołajewska, 2011).

Kinesiology Taping method has local and systemic effects on the human body without showing any invasiveness. These factors determine the attractiveness of methods and its application in the states accompanied by pain. KT effectiveness was confirmed in athletes experiencing pain after spinal-stress training (Garczyński et al., 2013; Merino-Marban et al., 2013). It was also shown that KT helps to reduce chronic lumbar-sacral pain (Bae et al., 2013; Castro-Sánchez et al., 2012; Lemos et al., 2014; Paolini et al., 2011) and Czyżewski et al. found that KT decreases pain in the case of rib fractures and exhibits an anti-swelling properties (Czyżewski et al., 2012).

The literature suggests that somatotype (structural features) is related to body's homeostasis and exercise capacity (Chaouachi et al., 2005; Lewandowska et al., 2011; Özkan et al., 2012). Many authors draw attention to the relationship between athletes sport efficacy and their somatotype (Brocherie et al., 2014; Carvajal et al., 2009; Fidelix et al., 2014; Purenović-Ivanović, Popović, 2014).

There has been increased interest in healthy lifestyle and fitness for several years. Many people starting intensive training experience DOMS being the reason for discontinuation of activity. The aim of this study was to evaluate the analgesic efficacy of Kinesiology Taping in DOMS and to determine whether somatotype is related to the analgesic effectiveness of the method.

\section{Materials and Methods}

\section{Participants}

The study group consisted of 20 people, aged $27.7 \pm 6.4$ years, with a moderate or high level of physical activity. All participants declared their state of health as good. People taking part in the survey were familiar with its purpose and course and gave written consent which was prepared in compliance with the ethical principles formulated by Kruk (2013). The project was positively evaluated by the Bioethics Commission of the Pomeranian Medical University in Szczecin (Resolution No. KB-0012/35/15). 


\section{Methods}

In order to assess the degree of physical activity the International Physical Activity Questionnaire (IPAQ) short version was applied. People with at least moderate level of physical activity were included into the study group. Somatotype was evaluated by Heath-Carter method. In case of ecto and mesomorphic types 7-point scale Sheldon assessment was expanded to 9 and in case of endomorphic to 12 degrees. The subjects underwent training concentrated on arms or legs, once. The training was conducted with an emphasis on eccentric muscle work using free weights. The physical activity was tailored to the individual capabilities of each of the respondents. The power used in the training ranged from 60 to $90 \%$ of the maximum possible load.

While DOMS occurred, in each of the participants, we applied K-Active Tape (Nitto Denko, Japan), in the specified muscle area, where the highest pain was expressed. Then participants were asked to fill in two identical surveys including the visual-analogue scale (VAS), which evaluated the pain in limbs with and without the application of KT. The evaluation was carried out for five days, one time a day at the same time time, starting 5 hours after the KT application.

To determine whether the method exhibits analgesic activity in DOMS we analyzed the intensity of pain each day. The average values reflecting the intensity of pain each day were compared between the two limbs (with and without application) using the following designations: the difference in the first measurement of $\Delta 1$, by next measurement $\Delta n$ etc. Additionally, we analyzed the difference in the intensity of pain (scale 1-10) between limbs on the first (5 hours after application) and on the last day, $\triangle$ VAS.

In addition, the influence of participants somatotype on KT analgesic effectiveness was analyzed. In order to do this we compared the somatotype with $\triangle$ VAS separately for the area with and without KT application.

\section{Statistical analyses}

Continuous variables were characterized by the average value (M) and standard deviation (SD). In the case of qualitative variables there was amount (n), also expressed in the percentage (\%) given. To assess the association of somatotype with analgesic efficacy of KT, ANOVA test was used. All the analyses were performed using Stat View Package Version 5.0 (SAS Institute Inc., Cary, NC, USA). The level of significance was set at $p<0.05$.

\section{Results}

In $18(90 \%)$ of the 20 participants, the physical activity level was assessed as high. There were $2(10 \%)$ subjects with moderate level of physical activity. Using anthropometric measurements we identified four types of somatotype: ectomorphic $(n=3 ; 15 \%)$ endomorphic $(n=4 ; 20 \%)$, mesomorphic $(n=8 ; 40 \%)$ and mixed $(n=5 ; 25 \%)$.

After strength training we applied KT and one respondent received one application. KT were applied to the following muscles: gastrocnemius $(n=3 ; 15 \%)$ quadriceps femoris $(n=8 ; 40 \%)$, biceps femoris $(n=3 ; 15 \%)$ gluteus maximus $(n=2 ; 10 \%)$, biceps brachii $(n=2 ; 10 \%)$, pectoralis major $(n=1 ; 5 \%)$ and deltoid $(n=1 ; 5)$.

Comparing the intensity of pain perception between the area with and without KT we observed smaller, statistically significant $(p<0.05)$ sensation of pain in case of KT application, since the first day until the end of the study. The results are given in Table 1. There was no effect of participants somatotype on analgesic efficacy of KT $(p>0.05)$. The results are shown in Figures 1 and 2 . 
Table 1. The differences in the intensity of DOMS

\begin{tabular}{|c|c|c|c|c|c|c|c|}
\hline & \multicolumn{3}{|c|}{ Area without KT application } & \multicolumn{3}{|c|}{ Area with KT application } & \multirow{2}{*}{$p$} \\
\hline & $\mathrm{M} \pm \mathrm{SD}$ & $\min$. & $\max$. & $M \pm S D$ & $\min$. & $\max$. & \\
\hline VAS 1 & $6.75 \pm 1.94$ & 2 & 10 & $6.20 \pm 1.90$ & 1 & 8 & 0.0020 \\
\hline VAS 2 & $6.70 \pm 1.89$ & 2 & 9 & $5.55 \pm 1.95$ & 1 & 8 & 0.0001 \\
\hline VAS 3 & $5.70 \pm 1.75$ & 2 & 8 & $4.35 \pm 1.92$ & 1 & 7 & $<0.0001$ \\
\hline VAS 4 & $4.25 \pm 1.91$ & 1 & 8 & $2.90 \pm 1.71$ & 0 & 6 & 0.0002 \\
\hline VAS 5 & $2.75 \pm 1.99$ & 0 & 8 & $1.45 \pm 1.53$ & 0 & 5 & 0.0001 \\
\hline$\triangle V A S$ & $4.00 \pm 2.20$ & -1 & 8 & $4.75 \pm 2.15$ & 0 & 8 & 0.0039 \\
\hline
\end{tabular}

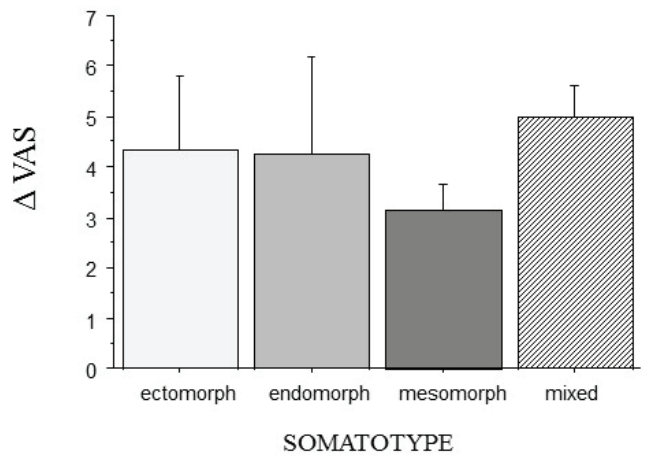

Figure 1. The somatotype in relations to DOMS reduction in limbs without KT application ( $p>0.05)$. Bars indicate standard errors

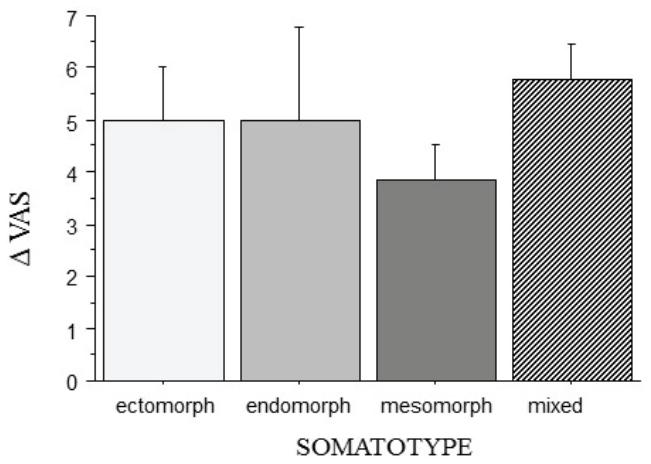

Figure 2. The somatotype in relations to DOMS reduction in limbs with KT application $(p>0.05)$.

Bars indicate standard errors 


\section{Discussion}

In 2010 Tiffert (2010) described that KT application results in tissue relief, increased blood flow and lymph circulation thus accelerating the healing process and pain reduction. In present study we observed a reduction of pain since the first day of KT application and a statistically significant difference $(p<0.05)$ was maintained throughout the whole study period. The results of our study are therefore consistent with the findings of tests carried out by Nosaka and Clarkson. They induced DOMS in upper limbs in a group of untrained students by using strength eccentric exercises in two sessions, two weeks apart. The subjects were divided into two groups, during the first series of exercises KT wasapplied in the first group, while the second session in the second group. The results obtained by the researchers confirmed the effectiveness of KT in removing pain, reducing muscle stiffness and increasing range of motion and strength (Nosaka, Clarkson, 1990).

Other researchers analyzed the effectiveness of KT in DOMS only in the study group. The control group consisted of people who carried out observations of DOMS regression without any therapeutic method. The intensity of pain was assessed using VAS scale; before KT application and in 24, 48 and 72 hours after the treatment. It was found that KT accelerates the pain and has a positive effect on the muscle strength. Moreover, it was proved that thickened, as a result of DOMS, muscles return to proper morphology faster when applying KT patch (Lee et al., 2015). Bae et al. also confirmed the effectivenes of KT in abolishing pain as well as in supporting the correct perception of temperature (Bae et al., 2014a, 2014b). Nevertheless, there is also a body of evidence indicating no positive effect of KT in DOMS. Among many works on the analgesic efficacy there are also ones which have not confirmed the positive effect of KT in DOMS. Ozmen et al. studied a group of female students with low physical activity and reported no statistically significant efficacy of KT in case of DOMS. The authors noted, however, that 48 hours after the application muscle flexibility increased (Ozmen et al., 2015).

Pain is a subjective sensation thus the opinion of the authors of this study states that the difference can be shown only in the same sample, when all other modifiable factors are eliminated. Moreover, in case of works by Nosaka and Clarkson (1990) and Ozmen et al. (2015) too short period of time between the training sessions could influence the results. In recent years it was shown that muscle tissue affected by DOMS returns completely to its homeostasis within 6 weeks (Hyldahl, Hubal, 2014). We therefore assume that performing experiments in people previously adapted to a more intensive effort could interfere with the results obtained by the researchers.

According to the literature, one's metabolism depends on individual somatotype (Harmon, 2010). In 2010, Harmon found that people of endomorphic and then mesomorphic somatotype are most likely to develop DOMS. In contrast, ectomorphic people show the greatest resistance to pain (Harmon, 2010). In our studies, we confirmed no impact of the somatotype on the analgesic efficacy of KT. This may be due to small sample size and the fact that $25 \%$ of the study group $(n=5)$ presented a mixed somatotype.

The present study confirms that KT exhibits an analgesic effect in DOMS. According to the literature KT also contributes to an increase in range of muscle motion and strength, improve surface tension and reduction in muscle tone. These phenomena suggest that KT in DOMS acts not only mechanically but also affects physiological processes involved in the regeneration of damaged muscle tissue (Bae et al., 2014a, 2014b; Nosaka, Clarkson, 1990; Lee et al., 2015; Ozmen et al., 2015). 


\section{References}

Armstrong, R.B., Warren III, G.L. (1993). Strain-induced skeletal muscle fibre injury. In: D. Macleod (ed.), Intermittent high intensity exercise: preparation stresses and damage limitation, London: E \& FN Spon.

Bae, S.H., Lee, J.H., Oh, K.A., Kim, K.Y. (2013). The Effects of Kinesio Taping on Potential in Chronic Low Back Pain Patients Anticipatory Postural Control and Cerebral Cortex. Journal of Physical Therapy Science, 25, 1367-1371. DOI: 10.1589/.jpts.25.1367.

Bae, S.H., Lee, Y.S., Kim, G.D., Kim, K.Y. (2014a). Quantitative Evaluation of Delayed Onset Muscular Soreness According to Application of Kinesio Taping. Advanced Science and Technology Letters, 47, 387-390.

Bae, S.H., Lee, Y.S., Kim, G.D., Kim, K.Y. (2014b). The Effects of Kinesio-Taping applied to Delayed Onset Muscle Soreness on changes in pain. International Journal of Bio-Science and Bio-Technology, 3, 133-142.

Brocherie, F., Girard, O., Forchino, F., Al Haddad, H., Dos Santos, G.A., Millet, G.P. (2014). Relationships between anthropometric measures and athletic performance, with special reference to repeated-sprint ability, in the Qatar national soccer team. Journal of Sports Sciences, 32, 1243-1254. DOI: 10.1080/02640414.2013.862840.

Carvajal, W., Ríos, A., Echevarría, I., Martínez, M., Miñoso, J., Rodríguez, D. (2009). Body Type and Performance of Elite Cuban Baseball Players. MEDICC Review, 11, 15-20.

Castro-Sánchez, A.M., Lara-Palomo, I.C., Matarán-Peñarrocha, G.A., Fernández-Sánchez, M., Sánchez-Labraca, N., Arroyo-Morales, M. (2012). Kinesio Taping reduces disability and pain slightly in chronic non-specific low back pain: a randomised trial. Journal of Physiotheraphy, 58, 89-95. DOI: 10.1016/S1836-9553(12)70088-7.

Chaouachi, M., Chaouachi, A., Chamari, K., Chtara ,M., Fek, Y., Amri, M. (2005). Effects of dominant somatotype on aerobic capacity trainability. British Journal of Sports Medicine, 39, 954-959.

Cheung, K., Hume, P.A., Maxwell, L. (2003). Delayed Onset Muscle Soreness: treatment strategies and performance factors. Sports Medicine, 33, 145-164.

Czyżewski, P., Hałas, I., Kopytiuk, R., Domaniecki, J., Szczepkowski, M. (2012). Zastosowanie metody Kinesiology Taping w zmniejszeniu bólu po złamaniu żeber - doniesienie wstępne. Postępy Rehabilitacji, 4, 29-35.

Dutto, D.J, Braun, W.A. (2004). DOMS-associated changes in ankle and knee joint dynamics during running. Medicine \& Science in Sports \& Exercise, 36, 560-566.

Fidelix, Y.L., Berria, J., Ferrar, E.P., Ortiz, J.G., Cetolin, T., Petroski, E.L. (2014). Somatotype of Competitive Youth Soccer Players From Brazil. Journal of Human Kinetics, 42, 259-266. DOI: 10.2478/hukin-2014-0079.

Garczyński, W., Lubkowska, A., Dobek, A. (2013). Zastosowanie metody Kinesiology Tapingu w sporcie. Journal of Health Sciences, 9, 233-246.

Garrett, J. (1996). Muscle strain injuries. American Journal of Sports Medicine, 24, 2-8.

Gomes, R.V., Santos, R.C.O., Nosaka, K., Moreira, A., Miyabara, E.H., Aoki, M.S. (2014). Muscle damage after a tennis match in young players. Biology of Sport, 31, 27-32. DOI: 10.5604/20831862.1083276.

Gulick, D.T., Kimura, I.F. (1996). Delayed onset muscle soreness: what is it and how do we treat it? Journal of Sport Rehabilitation, 5 , 234-243.

Harmon, A.B. Jr. (2010). Effects of Transcutaneous Electrical Stimulation on Acoustic and Perceptual Measures of Vocal Function across Body Types. Electronic Theses. Treatises and Dissertations 2010, paper 4262.

Hedayatpour, N., Falla, D. (2014). Delayed onset of vastii muscle activity in response to rapid postural perturbations following eccentric exercise: a mechanism that underpins knee after eccentric exercise? British Journal of Sports Medicine, 48, 429-434. DOI: 10.1136/bjsports-2012-092015.

Hough, T. (1902). Ergographic studies in muscular soreness. American Journal of Physiology - Legacy Content, 7, 76-92.

Hyldahl, R.D., Hubal, M.J. (2014). Lengthening our perspective: morphological, cellular, and molecular responses to eccentric exercise. Muscle Nerve, 49, 155-170. DOI: 10.1002/mus.24077.

Kase, K. (ed.). (2000). Illustrated Kinesio Taping. Universal Printing \& Publishing.

Kanda, K., Sugama, K., Hayashida, H., Sakuma, J., Kawakami, Y., Miura, S. et al. (2013). Eccentric exercise-induced delayed-onset muscle soreness and changes in markers of muscle damage inflammation. Exercise Immunology Review, 19, 72-85. 
Kruk, J. (2013). Good scientific practice and ethical principles in scientific research and higher education. Central European Journal of Sport Sciences and Medicine, 1, 25-29.

Lee, H., Petrofsky, J.S., Laymon, M., Yim, J.E. (2013). A Greater Reduction of Anterior Cruciate Ligament Elasticity in Women Compared to Men as a result of Delayed Onset Muscle Soreness. The Tohoku Journal of Experimental Medicine, 231, 111-115.

Lee, Y.S., Bae, S.H., Hwang, J.A., Kim, K.Y. (2015). The effects of kinesio taping on architecture, strength and pain of muscles in delayed onset muscle soreness of biceps brachii. Journal of Physical Therapy Science, 27, 457-459. DOI: 10.1589/jpts.27.457.

Lemos, T.V., Gonçalves, Albino A.C., Matheus, J.P.C., de Melo Barbosa, A. (2014). The Effect of Kinesio Taping in Forward Bending of the Lumbar Spine. Journal of Physical Therapy Science, 26, 1371-1375. DOI: 10.1589/jpts.26.1371.

Lewandowska, J., Buśko, K., Pastuszak, A., Boguszewska, K. (2011). Somatotype Variables Related to Muscle Torque and Power in Judoists. Journal of Human Kinetics, 30, 21-28. DOI: 10.2478/v10078-011-0069-y.

Merino-Marban, R., Mayorga-Vega, D., \& Fernandez-Rodriguez, E. (2013). Effect of Kinesio Tape Application on Calf Pain and Ankle Range of Motion in Duathletes. Journal of Human Kinetics, 37, 129-135. DOI: org/ 10.2478/hukin-2013-0033.

Mikołajewska, E. (ed.). (2011). Kinesiotaping. Warszawa: PZWL.

Nosaka, K., Clarkson, P.M. (1996). Changes in indicators of inflammation after eccentric exercise of the elbow flexors. Medicine \& Science in Sports \& Exercise, 28, 953-961.

Özkan, A., Kayıhan, G., Köklü, Y., Ergun, N., Koz, M., Ersöz, G. et al. (2012). The Relationship Between Body Composition, Anaerobic Performance and Sprint Ability of Amputee Soccer Players. Journal of Human Kinetics, 35, 141-146. DOI: 10.2478/ v10078-012-0088-3.

Ozmen, T., Aydogmus, M., Dogan, H., Acar, D., Zoroglu, T., Willems, M. (2016). The Effect of Kinesio Taping® on Muscle Pain, Sprint Performance, and Flexibility in Recovery From Squat Exercise in Young Adult Women. Journal of Sport Rehabilitation, 25, 7-12. DOI: 10.1123/jsr.2014-0243.

Paolini, M, Bernetti, A., Fratocchi, G., Mangone, M., Parrinello, L., del Pilar Cooper, M. et al. (2011). Kinesio Taping applied to lumbar muscles influences clinical and electromyographic characteristics in chronic low back pain patients. European Journal of Physical and Rehabilitation Medicine, 47, 237-244.

Purenović-Ivanović, T., Popović, R. (2014). Somatotype of Top-Level Serbian Rhythmic Gymnasts. Journal of Human Kinetics, 40, 181-187. DOI: 10.2478/hukin-2014-0020.

Serinken, M.A., Gencoglu, C., Kayatekin, B.M. (2013). The Effect of Eccentric Exercise-Induced Delayed-Onset Muscle Soreness on Positioning Sense and Shooting Percentage in Wheelchair Basketball Players. Balkan Medical Journal, 30, 382-386. DOI: 10.5152/balkanmedj.2013.007.

Stauber, W.T. (1989). Eccentric action of muscles: physiology, injury and adaptation. In: K.P. Pandolf (ed.), Exercise and sport science reviews. Baltimor: Williams and Wilkins.

Tiffert, M. (2010). Kinesiology Taping - teoria, metodyka, przykładowe aplikacje w konkretnych dysfunkcjach. Praktyczna Fizjoterapia i Rehabilitacja, 2, 48-53.

Cite this article aS: Kruszyniewicz, J., Skonieczna-Żydecka, K., Sroka, R., Adler, G. (2016). The Analgesic Efficacy of Kinesiology Taping in Delayed Onset Muscle Soreness (DOMS). Central European Journal of Sport Sciences and Medicine, 13 (1), 73-79. DOI: 10.18276/cej.2016.1-07. 
